
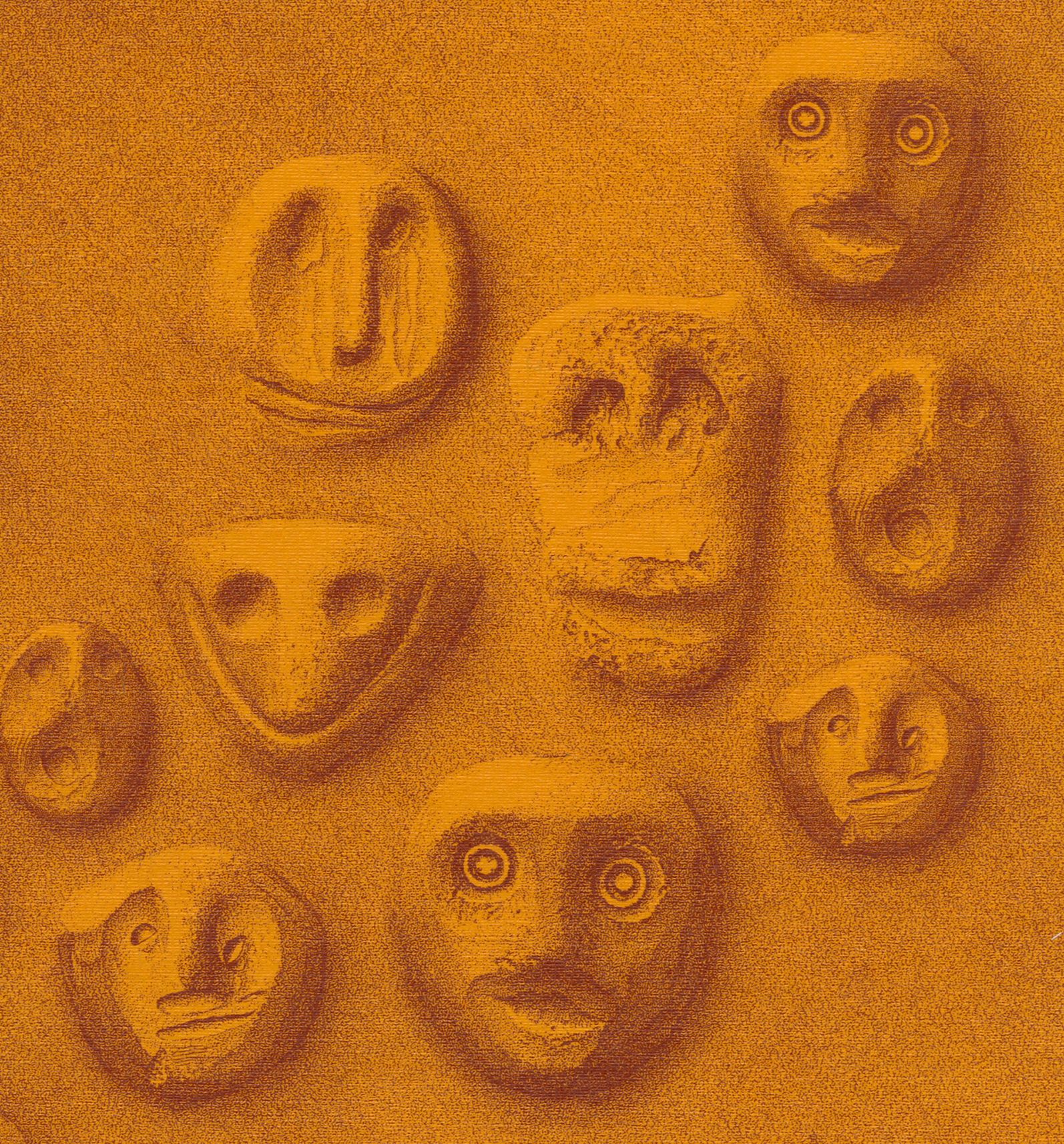

5) - Nethe

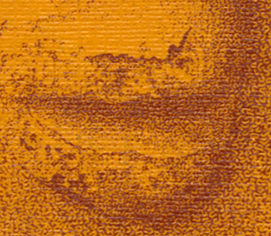




\section{KUML 1990}

Årbog for Jysk Arkæologisk Selskab

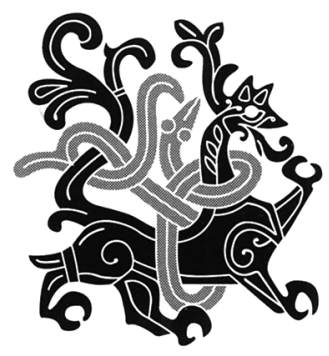

With summaries in English

I kommission hos Aarhus Universitetsforlag, Århus 
Redaktion: Poul Kjarum

Redaktionsudvalg:

Jens Henrik Bech, Thisted

Steen Hvass, Vejle

Stig Jensen, Ribe

Erik Johansen, Aalborg

Erik Jorgensen, Haderslev

Hans Jorgen Madsen, Arhus

Omslag: Lerhoveder fra celdre jernalder

Udgivet med stotte af Statens Humanistiske Forskningsråd

Omslag: Jens Kirkeby

Grafisk tilretteloggelse: Elsebet Morville

Tryk: Special-Trykkeriet Viborg a-s

Skrift: Bembo 11/12

Papir: Stora G-Print $120 \mathrm{~g}$

Copyright 1992 by Jysk Arkceologisk Selskab

ISBN 87-7288-562-9

ISSN 0454-6245 


\section{Indhold/Contents}

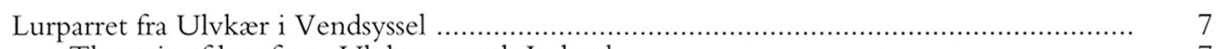

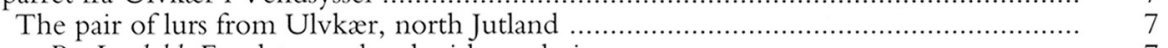

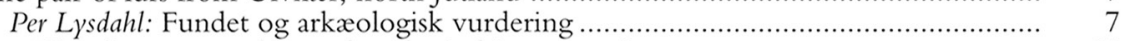

The discovery and its archaeological interpretation ................................. 21

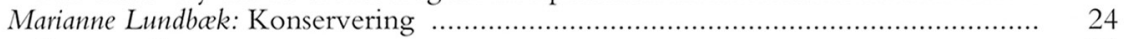

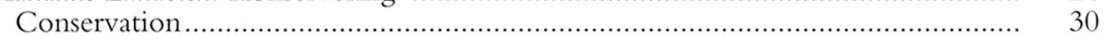

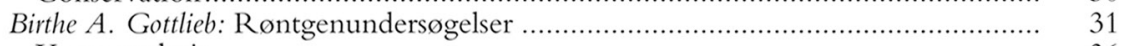

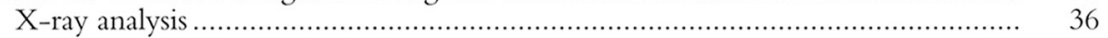

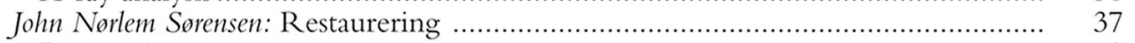

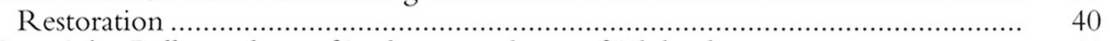

Bent Aaby: Pollenanalyser af jordprøver udtaget af Ulvkærlurerne ............................. 41

Pollen analysis of peat samples from the Ulvkær lurs .............................. 42

Erik Johansen: En brandgravplads med smykkefund fra førromersk jernalder.................... 45

A cremation cemetery with ornaments from the pre-Roman Iron Age ...................... 56

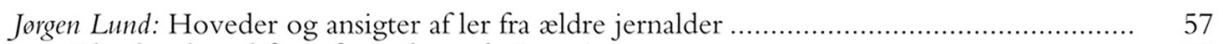

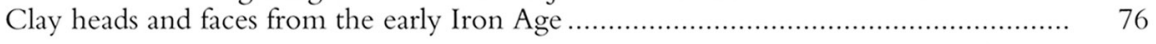

Lise Bender Jørgensen: Hørvævninger og oldtidsvæve ......................................... 77

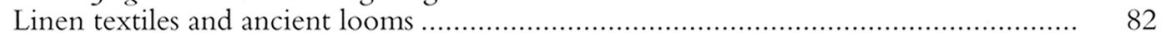

Per Ethelberg: To grave fra Højvang, Sønderjylland .............................................. 85

Dendrodatering og absolut kronologi

Two graves from Højvang in southern Jutland; dendrodating and

absolute chronology

John Brinch Bertelsen: Nederby på Fur - en landsby grundlagt i yngre jernalder

Et bidrag til belysning af vikingetidsbebyggelsen i den vestlige del af Limfjorden ........

Nederby on Fur, a village founded in the later Iron Age. A contribution to

knowledge of Viking settlement in the western Limfjord

Torben Nilsson: Stentinget. En indlandsbebyggelse med handel og håndværk fra

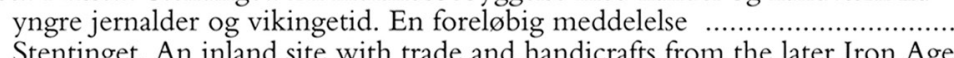

Stentinget. An inland site with trade and handicrafts from the later Iron Age.

A preliminary notice.

H. J. Madsen og Per Vegger: Karby på Mors. En landsby fra vikingetiden

Karby on Mors, a Viking village ....

En vikingetidssølvskat fra Brokhøj, Gjerrild Klint

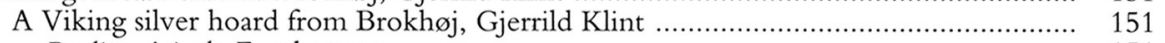

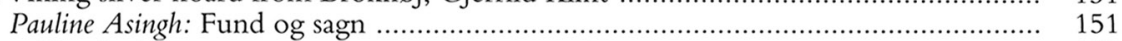

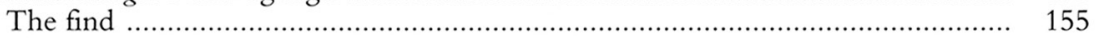

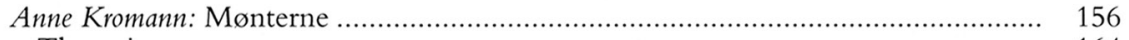

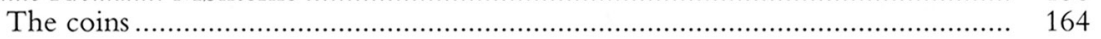




\section{Restaurering}

Førhen har det været almindelig, anerkendt praksis at restaurere temmelig hårdhændet på bronzer, og i særdeleshed på lurer. En ganske betydelig del af de lurer vi kender, var ved fremdragningen stærkt fragmenterede, bulede, vredet ud af form, og ofte manglede stykker. I bestræbelserne på at skabe seværdige udstillings- og forskningsobjekter, har man hamret og banket, glødet og loddet, filet og nedsænket i syrebade, pudset og patineret på de stakkels lurer. Denne behandling fremgår ikke umiddelbart, når man betragter lurerne i dag, idet dette arbejde for det meste har været udført af særdeles kompetente håndværkere, - og der er da også kommet pæne, blanke instrumenter ud af bestræbelserne.

Disse metoder har vi forladt for længe siden, idet holdningen nu er den, at man ikke bør udsætte en museumsgenstand for en irreversibel behandling, der medfører ændringer i materialet. Det er indlysende, at ændringer i materialet vanskeliggør senere analyser, og dermed hæmmer den kommende forskning ganske meget. Det er et erkendt faktum, at strukturen i metaller ændres ved opvarmning, og det betyder, at metallurgiske analyser foretaget på lurer, der har været udsat for lodning eller glødning er ubrugelige.

Vore kilder til viden om den behandling man har udsat lurerne for førhen er, mildt sagt, mangelfulde. På trods af en forholdsvis god dokumentation omkring fundforholdene har man kun ganske få oplysninger fra datidens konservator/restaurator, der kan give et fingerpeg om holdningen til, hvor langt man kunne gå. Det var før konserveringsrapporternes tid, - men lidt har vi da.

Af H.C. Broholm (1958): Bronzelurerne i Nationalmuseet fremgår følgende:

Om Boeslunde: En venstresvungen lur, der nu, efter at fragmenterne har været glødede, har bronzens naturlige farve.

Om Folvisdamlurerne: Her nævnes en kobbersmed, der filede et stykke ud af den ene og foretog en klodset restaurering af den anden.

Om Brudevæltelurerne: Hovedrøret viser et par kraftige buler fremkaldt ved et stød, samt et hul i væggen, der nu er tætnet ved lodning.

Om Rørlykkelurerne: Metallet er afsyret og har nu sin naturlige, lysegule farve.

Man må formode, at man forholdsvis hurtigt efter at have modtaget lurerne på museet har iværksat konserveringsarbejdet, og umiddelbart herefter har foretaget den nødvendige restaurering med henblik på den videre forskning og udstilling. Da de sidste lurfund blev gjort i 1894, er det temmelig længe siden, man har udført restaureringsarbejder på de fleste lurer. Vi har dog kendskab til, at 4 lurer, 2 fra Boeslunde samt 2 fra Lommelev, er restaurerede i 1940, - efter at have ligget på Nationalmuseet i stumper i 100 år!

Når man til disse metoder lægger en afpudsning og patinering, er det indlysende, at det ikke kun er en ændring i metallets struktur, men også lurernes overflader må nødvendigvis lide skade. Værdifulde bearbejdningsspor kan gå tabt, vigtige detaljer i en eventuel dekoration kan komme til at fremstå slørede og uden stringens. Det virker derfor temmelig ejendommeligt, at man i ét tilfælde, Radbjerglurerne, har udvist den allerstørste omtanke ved restaureringen: "at der i dem er anbragt messingrør, der svarer til instrumenternes krum- 


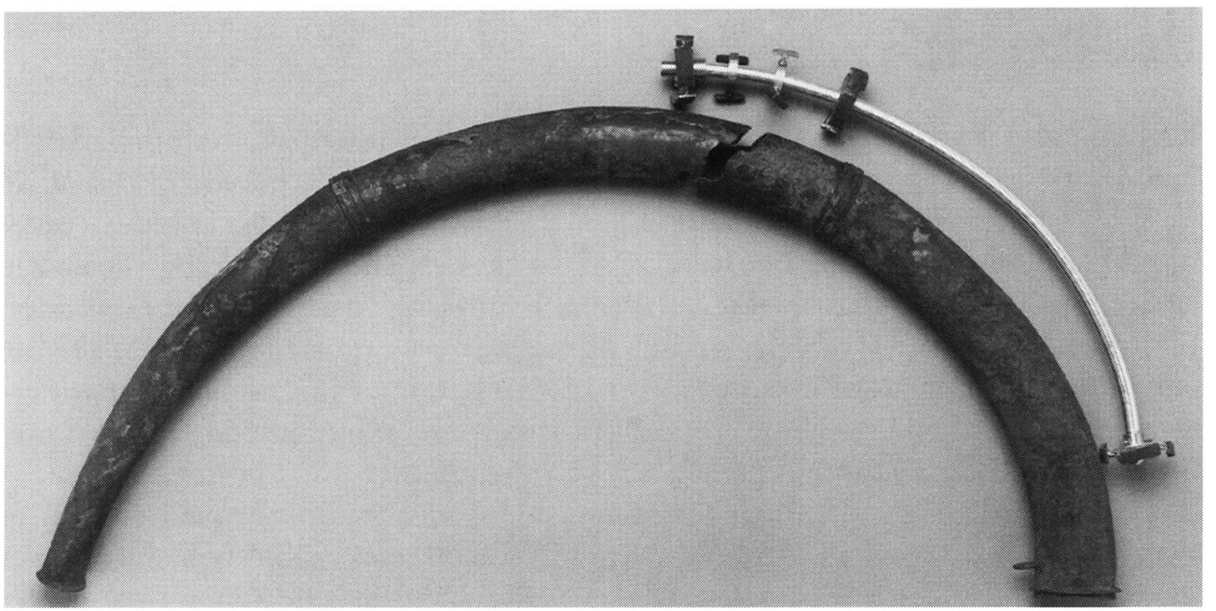

Fig. 1. Holder, fremstillet af aluminium, monteret med centreringsstykker.

Supporting tube of aluminium with adjustable centering device.

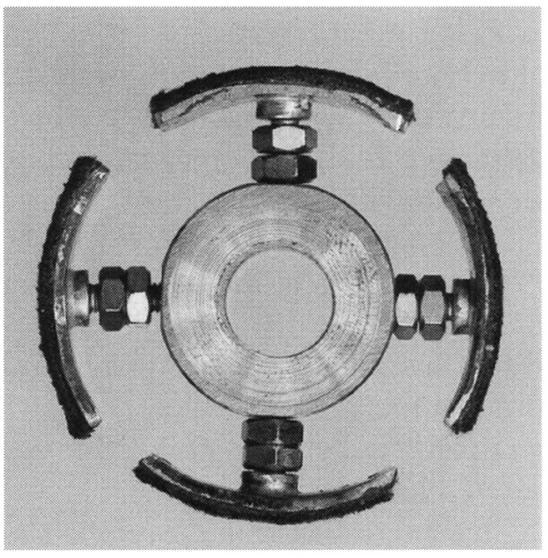

Fig. 2. Centreringsstykke med tryksko og gevindspindler.

The centering device with threaded rods ending in leather-covered caps.

Fig. 4. Den færdige lur 1, klar til udstilling. Lur 1 ready for exhibition.

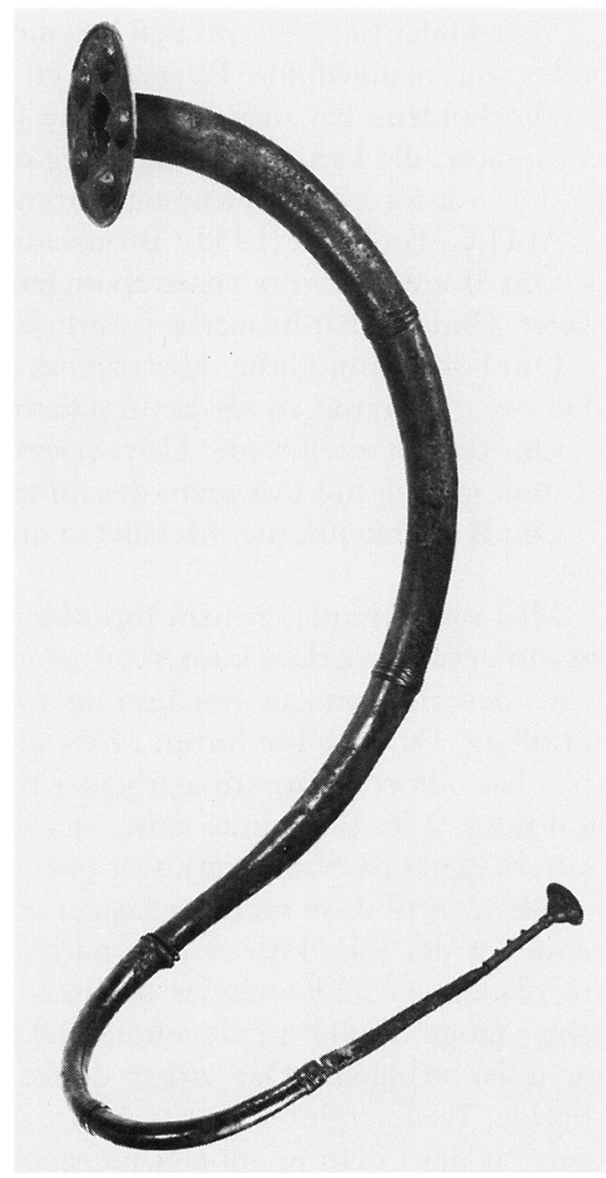




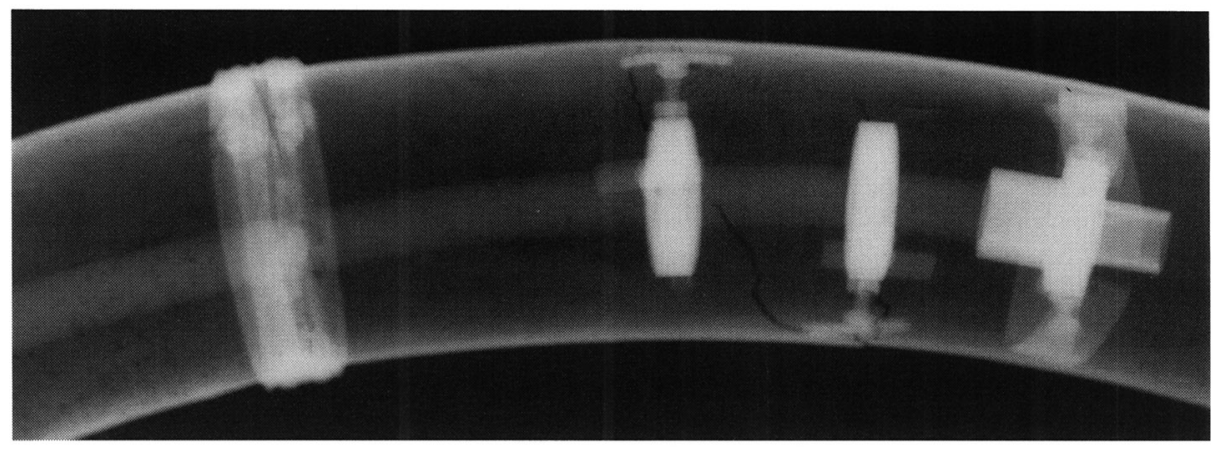

Fig. 3. Røntgenoptagelse af holder indsat i lur 1.

$\mathrm{X}$-ray showing lur with support assembly inside.

ning, og herpå er de løse stykker befæstede ved hjælp af bivoks, der er absolut neutralt og ikke angriber metallet". Man får den tanke, at nogle har haft en fornemmelse af, at undersøgelsesmetoderne ville udvikle sig til det mere præcise stade, de befinder sig på i dag.

Stillet overfor opgaven, at skulle restaurere lur 1 fra Ulvkær på baggrund af den viden og holdning man har i dag, er der følgende krav, der må overholdes: 1) ingen ændringer i materialets form og struktur, 2) ikke at anvende sammenføjningsmetoder som lodning, svejsning o.lign. Løsningen, vi valgte, bestod i at tildanne og forme en rund metalstang (fig. 1), således at den følger lurens krumning og drejning i en centerlinie gennem rørene, fra mundstykke til prydplade. En sådan metalstang må naturligvis have en vis stivhed og styrke, idet den ikke alene skal fiksere de enkelte dele $\mathrm{i}$ forhold til hinanden, men også optage de kræfter, der vil opstå på langs, når man spænder de enkelte dele af luren sammen. Aluminium viste sig at være et fortrinligt materiale til denne opgave, idet det er temmelig stift og ikke vejer noget af betydning.

For at fiksere denne metalstang, "holderen", i centrum af rørene måtte der fremstilles et antal centreringsstykker (fig. 2). Hvert centreringsstykke blev forsynet med 4 tryksko, omhyggeligt tildannede, ikke alene efter lurens indvendige diameter det pågældende sted (fig. 3), men også det forhold, at rørene er koniske, måtte der tages højde for. Med 4 gevindspindler blev centreringsstykkerne anbragt i rørene. Ved at forsyne holderen med et fingevind i hver ende var det nu muligt at spænde de enkelte lurdele sammen, idet centreringsstykkerne styrede brudfladerne ganske præcist på plads, og luren var hermed klar til udstilling (fig. 4). 


\title{
Restoration
}

The article describes a number of how roughly lurs were restored in the past, for instance by annealing, hammering out dents, and joining broken parts by means of hard soldering. The reason why these methods have been abandoned are briefly accounted for. It is furthermore

described how a newly found pair of lures from Ulvkær have been prepared for exhibition without use of methods causing changes of the material and thereby endangering future research.

\author{
Jolin Norlem Sorensen \\ Bevaringssektionen, Nati- \\ onalmuseet
}

Foto: Joln Lee (1-2), Birthe A. Gottlieb (3), Lennart Larsen (4) 